\title{
Reduction in inequalities in health insurance coverage and healthcare utilization among older adults in the Philippines after mandatory national health insurance coverage: trend analysis for 2003-2017
}

Kathryn Lizbeth Lucena Siongco, Keiko Nakamura* [D and Kaoruko Seino

\begin{abstract}
Background: Health policies in the Philippines have evolved in response to increasing health demands of older adults. However, there is a lack of research on equity among the ageing population in low-middle income countries. The objective of this study was to identify the trends in National Health Insurance Program (NHIP) coverage and healthcare utilization among older adults in the Philippines for the period from 2003 to 2017, during which NHIP expansion policies were implemented, focusing on reductions in socio-economic inequalities.

Methods: A literature search of policies for older adults and an analysis of four Philippine National Demographic and Health Surveys $(2003,2008,2013$, and 2017) with data from 25,217 older adults who were 60 years or older were performed. The major outcome variables were NHIP coverage, self-reported illness, outpatient healthcare utilization, and inpatient healthcare utilization. Inequalities in NHIP coverage and healthcare utilization according to wealth were evaluated by calculating the concentration index for individual years, followed by a regression-based decomposition analysis.

Results: NHIP coverage among older adults increased from 9.4 (2003) to 87.6\% (2017). Although inequalities according to wealth quintile were observed in all four surveys (all $P<0.001$ ), the concentration index declined from 0.3000 (2003) to 0.0247 (2017), showing reduced inequalities in NHIP coverage over time as observed for self-reported illness and healthcare utilization. NHIP coverage expansion for older adults in 2014 enabled equal opportunity for access to healthcare.
\end{abstract}

Conclusion: The passage of mandatory NHIP coverage for older Filipino adults in 2014 was followed by a reduction in inequality in NHIP coverage and healthcare utilization according to wealth.

Keywords: National Health Insurance Program, Healthcare utilization, Health policy, Inequalities, Older adults, Concentration index, Philippines

\footnotetext{
* Correspondence: nakamura.ith@tmd.ac.jp

Department of Global Health Entrepreneurship, Division of Public Health, Graduate School of Medical and Dental Sciences, Tokyo Medical and Dental University, Yushima 1-5-45, Bunkyo-ku, Tokyo 113-8519, Japan
}

C C The Author(s). 2020 Open Access This article is licensed under a Creative Commons Attribution 4.0 International License, which permits use, sharing, adaptation, distribution and reproduction in any medium or format, as long as you give appropriate credit to the original author(s) and the source, provide a link to the Creative Commons licence, and indicate if changes were made. The images or other third party material in this article are included in the article's Creative Commons licence, unless indicated otherwise in a credit line to the material. If material is not included in the article's Creative Commons licence and your intended use is not permitted by statutory regulation or exceeds the permitted use, you will need to obtain permission directly from the copyright holder. To view a copy of this licence, visit http://creativecommons.org/licenses/by/4.0/. The Creative Commons Public Domain Dedication waiver (http://creativecommons.org/publicdomain/zero/1.0/) applies to the data made available in this article, unless otherwise stated in a credit line to the data. 


\section{Background}

The Philippines is considered to have an ageing population, similar to neighboring low- and middle-income countries (LMICs). The number of older adults (individuals aged 60 years or older) in the Philippines was reported be 8 million in 2017 and is estimated to increase to 21 million in 2050, accounting for $14 \%$ of the total population [1]. Given the growth of the older population, the demand for health services is increasing because of complex healthcare needs. In response to the increasing health demands of older adults, widespread efforts to improve health service delivery have been prominent in the Philippines as part of efforts to overcome socio-economic disparities in accessibility and availability of resources. Promoting fair financing and better health access across LMICs is necessary, as equitable access to healthcare services is a major public health challenge.

Social health insurance is a form of financing strategy when working towards equitable healthcare financing. The passage of Republic Act 7875 in 1995 created the Philippine Health Insurance Corporation (PhilHealth) and established the National Health Insurance Program (NHIP) with four initial membership categories: (i) formal sector, (ii) indigents, (iii) retirees, and (iv) individual. Through the years, the Department of Health (DOH) has provided a budget for PhilHealth to cover the contributions for indigent members. In 2012, the introduction of a "Sin Tax" Law, which is an excise tax on alcohol and tobacco products, allocated $85 \%$ of its revenues to healthcare [2], raising more than 1.2 billion USD (US dollars) in its first year and allowing the enrollment of 45 million Filipinos into PhilHealth [3]. Furthermore, as a result of the amendment of the "Expanded Senior Citizens Act of 2010 " in 2014, individuals aged 60 years or older were automatically enrolled into the NHIP and given free inpatient healthcare at government hospitals, thereby including "senior citizens" as a sector receiving NHIP coverage [4]. However, the urge to speed the expansion of coverage and the provision of free healthcare services to older adults holds the potential to impose a heavy financial burden on the Philippine health system, as previously experienced in Japan [5].

The Philippines' rapid economic growth has enabled advancements in healthcare in recent years; however, the health system remains fragmented. Large disparities in access to healthcare services remain, with differences observed among socio-economic groups, geographical regions, and rural/urban residences [6]. In a report on equity in health and healthcare in the Philippines, the poor were shown to suffer a greater burden of diseases [7], with high inequity regarding health outcomes between socioeconomic groups [6]; these data suggest that to promote vertical equity, healthcare must be concentrated among the poor, who have greater healthcare needs. However, the poor are unable to acquire necessary treatment according to their needs. All individuals should gain equitable access to healthcare in relation to need to achieve universal health coverage (UHC). Healthcare need is partly proxied by self-reported illness across socioeconomic groups, which is reported as an illness or symptom in the previous 30 days in household surveys [8]. In 2011, the Philippine government launched a UHC strategy to improve the overall health system and provide the poor with protection from financial risks [9]. To attain health equity, efforts must be directed in assessing the inequality in health and use of healthcare services of the vulnerable population [10], and socio-economic inequalities are reported through the prevalence of morbidities [11] and access to healthcare services $[12,13]$. The implementation of the NHIP and the expansion of coverage to include the older adult population are expected to reduce health inequalities through the provision of quality healthcare services and improved access to healthcare.

Despite the implementation of policies to increase NHIP coverage and access to healthcare, there remains a lack of research on equity among older adult populations in LMICs. This paper is the first to evaluate socioeconomic inequalities in health and healthcare utilization among older adults in the Philippines following the expansion of NHIP coverage as a step towards achieving UHC. We used population-based surveys from 2003 to 2017 to identify existing socio-economic inequalities in health and healthcare utilization among older adults in the Philippines. The objectives of this study were therefore to analyze the trends in NHIP coverage and healthcare utilization among older adults in the Philippines from 2003 to 2017, during which period the NHIP expansion policies were implemented, and to analyze the reduction in socio-economic inequalities, and present key developments in policies benefitting older adults in the Philippines in relation to NHIP coverage expansion and healthcare use.

\section{Methods}

This study consists of a literature search and an analysis of four Philippine National Demographic and Health Surveys conducted in 2003, 2008, 2013, and 2017.

\section{Literature search}

A literature search including data from PhilHealth, $\mathrm{DOH}$, and technical reports from national organizations (a total of 25 files) was performed to identify key developments in health policies benefitting older adults in the Philippines, even before the conception of the National Health Insurance Act in 1995. The chronological arrangement of policies presented in Table 1 shows the developments in relation to NHIP coverage and healthcare utilization among older Filipino adults. 
Table 1 Developments in health policies and laws concerning older adults in the Philippines

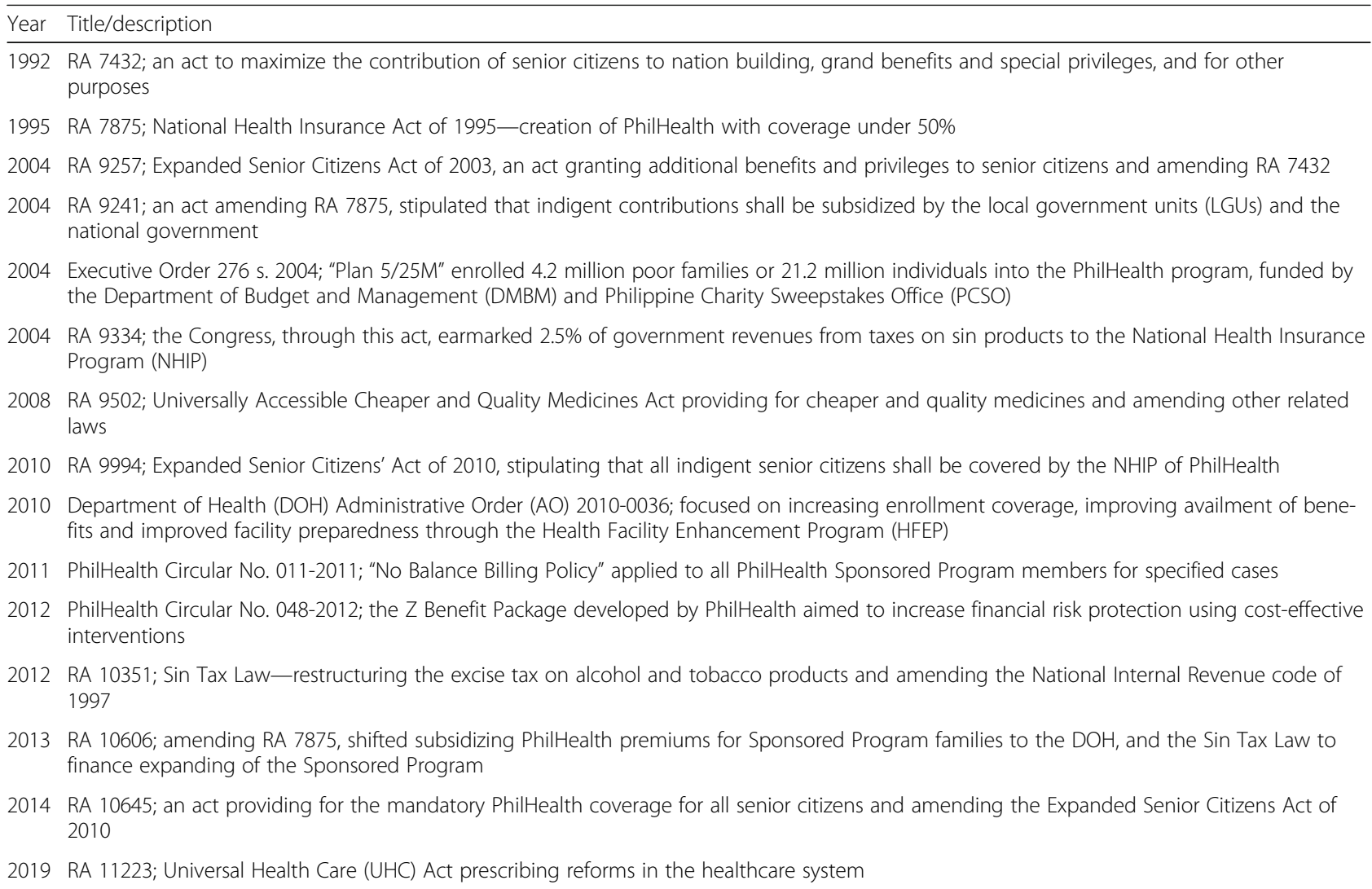

\section{Analysis of Philippine National Demographic and Health Survey data}

The analyses were based on representative, crosssectional Philippine National Demographic and Health Surveys (PDHS) conducted in 2003, 2008, 2013, and 2017 [14-17]. The following numbers of individuals aged 60 years and older were included in each survey: 3921 (2003), 4393 (2008), 5571 (2013), and 11,402 (2017). Cases with missing data for at least one study variable were excluded from the analysis (2003, 22 [0.6\%]; 2008, 8 [0.2\%]; 2013, 7 [0.1\%]; 2017, 33 $[0.3 \%])$. The final set of data for each survey used in the analysis included 3899 (2003), 4385 (2008), 5564 (2013), and 11,369 (2017) older adults.

\section{Variables}

The outcome variables of this study included National Health Insurance Program coverage, self-reported illness, and healthcare utilization, which were composed of outpatient care utilization and inpatient care utilization. Independent variables included socioeconomic characteristics such as age, gender, place of residence, educational attainment, wealth, number of household members, and relationship to household head.

\section{National Health Insurance Program (NHIP) coverage}

The outcome variable "health insurance" was measured by creating a binary variable for those with NHIP membership or PhilHealth, regardless of the category of membership (formal or informal, indigent, sponsored, lifetime, senior citizen, or overseas).

\section{Self-reported illness}

The outcome variable "self-reported illness" was composed of individuals who reported having at least one illness (non-communicable disease [NCD], communicable disease [CD], or injury) within the last 30 days prior to the interview. The variable was dichotomized as no $=0$ or yes $=1$. Individuals who reported having at least one illness in the last 30 days were categorized as "yes"; otherwise, the individuals were categorized as "no." Selfreported illness was excluded from the 2003 data because of a lack of information.

\section{Healthcare utilization (outpatient care utilization and inpatient care utilization)}

The measurement of healthcare utilization involved the following questions: for outpatient care, "Where was consultation/advice or treatment first sought for (name)'s illness/injury/check-up/laboratory tests in the last 30 days?"; and for inpatient care, "Where was (name) 
last confined in the last 12 months?" Those who responded with any public or private sector facility were coded as "care utilization (yes)" as performed in previous studies $[7,18]$. In contrast, those who responded with alternative medicine use, non-medical sectors, and others were coded as "non-utilization (no)." An analysis of outpatient care and inpatient care utilization was not performed for the 2003 data because of a lack of information. Each outcome variable was dichotomized as no $=0$ or yes $=1$.

\section{Socio-economic variables}

This study included individual and household characteristics that have been theoretically and empirically linked to health insurance ownership [19-21] and health and healthcare utilization outcomes $[19,20,22]$.

Each individual's age was categorized as follows: 6069 years, $70-79$ years, and 80 years or older. Gender was categorized as male or female. Place of residence was categorized as rural or urban. Education was categorized as no education, primary, secondary, or higher. Wealth was based on the computation of the DHS program per the specific survey year. Households were given scores derived using a principal component analysis based on the number and kinds of consumer goods they own. The wealth quintiles were compiled by assigning a household score and ranking to each household member and then dividing the distribution into five equal categories, each compromising $20 \%$ of the population. Relationship to the household head was categorized as self, spouse, or others. Number of household members was categorized as $1-2,3-4$, or 5 or more members. Marital status and occupation were not included because of a lack of information.

\section{Statistical analysis}

Descriptive statistics were initially used to analyze the outcome variables according to socio-economic characteristics for each of the four surveys. Chi-square test was used to measure the associations of NHIP coverage, selfreported illness, outpatient care utilization, and inpatient care utilization with older adult characteristics (Table 2).

\section{Concentration index}

The concentration index $(C)$ was estimated to quantify relative socio-economic inequalities in the NHIP coverage, selfreported illness, outpatient care utilization, and inpatient care utilization outcome variables (Table 3). $C$ represents twice the area between the concentration curve and the line of equality (the $45^{\circ}$ line), bounded between -1 and +1 [23]. A $C$ of 0 denotes no socio-economic-related inequality. When the curve lies above (below) the line of inequality, the index acquires a negative (positive) value, therefore indicating a disproportionate concentration of the health or healthcare utilization variable among the poor (rich). For example, a negative $C$ for self-reported illness denotes a higher value among the poor.

\section{Concentration curve}

The concentration curve (Fig. 1) was computed to illustrate the cumulative distribution of each health and healthcare utilization variable on the $y$-axis against the cumulative distribution of the population ranked according to wealth, beginning with the poorest and ending with the richest ( $x$-axis), graphically. If the health or healthcare utilization outcome was more concentrated among the poor, the concentration curve would lie above the line of equality. The farther the curve is above the $45^{\circ}$ line, the more concentrated the health or healthcare utilization variable is among the poor.

\section{Decomposition analysis of the concentration index}

A regression-based decomposition of the concentration index (Table 3) was performed to explain the contribution of each correlate to the reduction of socioeconomic inequalities across the population according to wealth [10]. The regression of the outcome variables was performed based on a linear additive regression of health/healthcare utilization. The mean of the health or healthcare utilization outcome and each of its correlates were estimated, followed by the calculation of the concentration indices for each correlate. To determine the effect of the contribution of each correlate on the outcome, the elasticities of the outcome variables with respect to each correlate evaluated at the mean value of each outcome variable (NHIP coverage, self-reported illness, outpatient care utilization, and inpatient care utilization) were calculated [24]. The contribution of each correlate in the model to the health and healthcare utilization inequality was quantified by calculating the absolute contribution to inequality of each correlate, considering the correlates' respective concentration indices, followed by the computation of the percentage distribution. Survey weights were used, and all the statistical analyses were performed using Stata 15 [23].

\section{Results \\ Key developments in health policies and laws for older adults}

Table 1 presents government policies to expand healthcare utilization and the population coverage of the NHIP among older adults. PhilHealth is a government-owned and operated corporation created in 1995 to implement the NHIP, with the aim of reducing out-of-pocket spending and inequities in health financing [25] and improving access to quality care. Financial assistance provided by the government is limited to the payment of premiums on behalf of disadvantaged groups, termed as 


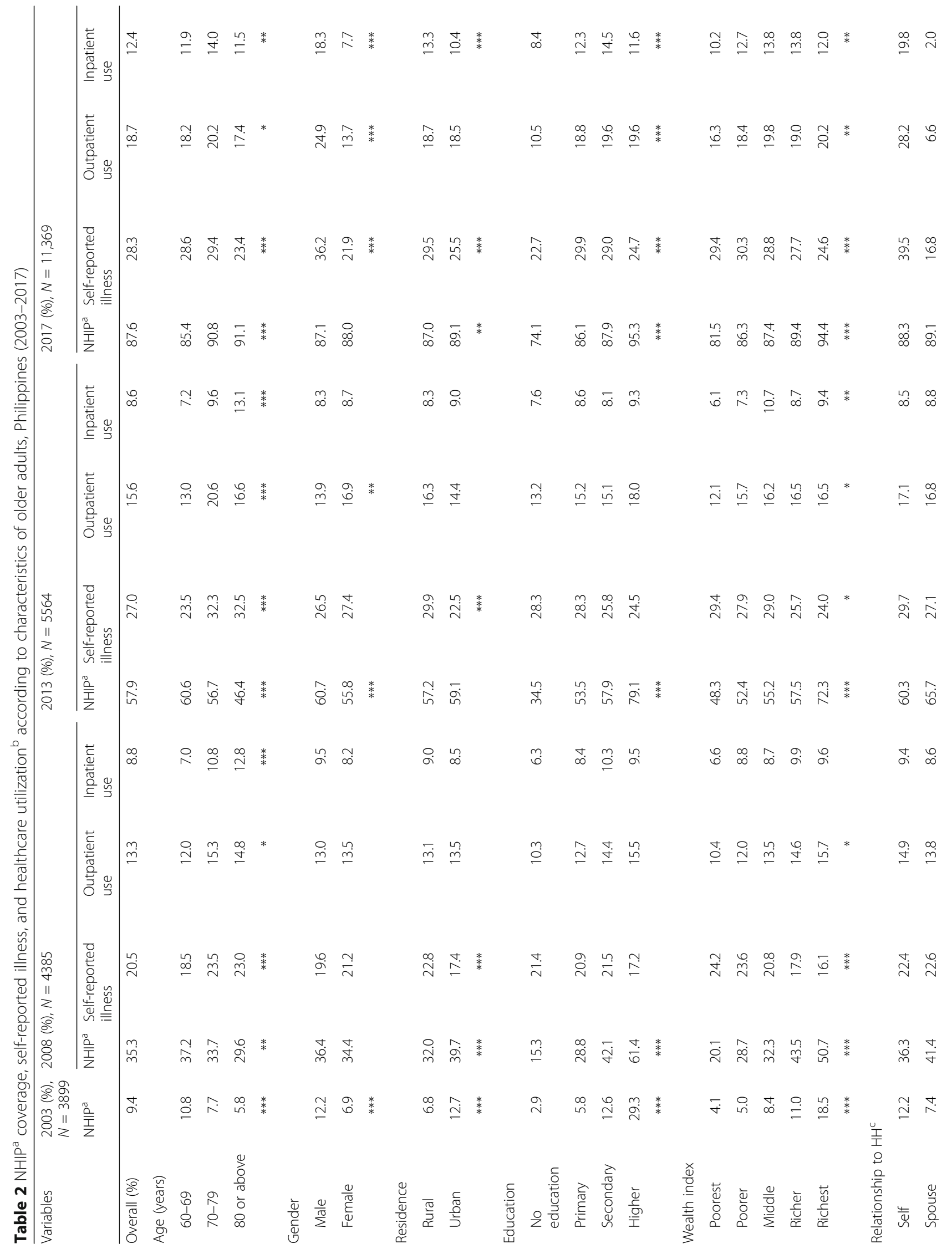


Siongco et al. Environmental Health and Preventive Medicine $\quad$ (2020) 25:17

Page 6 of 13

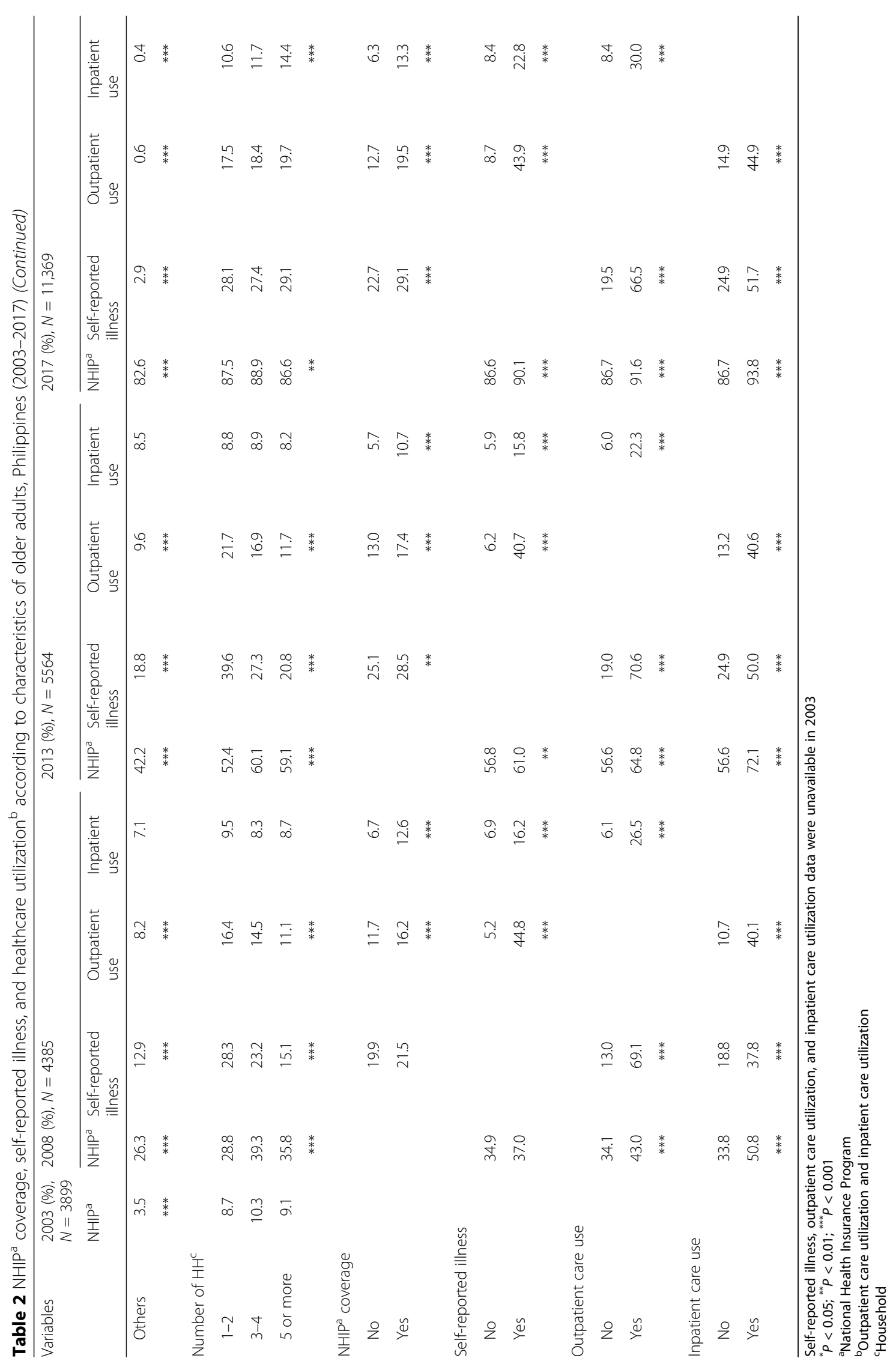


Table 3 Decomposition analysis of inequalities in NHIPa coverage, self-reported illness, and healthcare utilization ${ }^{\mathrm{b}}$ among older adults in the Philippines, 2003-2017

\begin{tabular}{|c|c|c|c|c|c|c|c|c|c|c|c|c|}
\hline \multirow[t]{2}{*}{ Variables } & \multicolumn{4}{|c|}{ Concentration index $(C)$} & \multicolumn{4}{|c|}{ Absolute contribution to $C^{c}$} & \multicolumn{4}{|c|}{ Percentage contribution to $C^{c}(\%)$} \\
\hline & 2003 & 2008 & 2013 & 2017 & 2003 & 2008 & 2013 & 2017 & 2003 & 2008 & 2013 & 2017 \\
\hline \multicolumn{13}{|l|}{ NHIP ${ }^{a}$ coverage } \\
\hline Concentration index & 0.3000 & 0.1803 & 0.0806 & 0.0247 & & & & & & & & \\
\hline \multicolumn{13}{|l|}{ Education } \\
\hline Primary & -0.123 & -0.187 & -0.196 & -0.228 & -0.010 & -0.029 & -0.022 & -0.015 & -3.3 & -15.8 & -27.3 & -60.0 \\
\hline Secondary & 0.264 & 0.228 & 0.143 & 0.105 & 0.024 & 0.023 & 0.008 & 0.004 & 8.0 & 12.8 & 9.6 & 14.6 \\
\hline Higher & 0.602 & 0.564 & 0.525 & 0.530 & 0.164 & 0.091 & 0.054 & 0.024 & 54.8 & 50.7 & 66.8 & 98.6 \\
\hline \multicolumn{13}{|l|}{ Wealth index } \\
\hline Poorer & -0.455 & -0.486 & -0.526 & -0.485 & -0.007 & -0.018 & 0.000 & -0.003 & -2.3 & -10.2 & -0.4 & -11.0 \\
\hline Middle & -0.054 & -0.106 & -0.137 & -0.114 & -0.004 & -0.005 & -0.001 & -0.001 & -1.4 & -2.5 & -1.1 & -3.1 \\
\hline Richer & 0.370 & 0.314 & 0.277 & 0.294 & 0.027 & 0.032 & 0.004 & 0.003 & 9.0 & 17.6 & 4.9 & 10.8 \\
\hline Richest & 0.793 & 0.771 & 0.746 & 0.755 & 0.118 & 0.088 & 0.044 & 0.016 & 39.3 & 48.7 & 54.6 & 64.7 \\
\hline \multicolumn{13}{|l|}{ Self-reported illness } \\
\hline Concentration index & & -0.0972 & -0.0474 & -0.0965 & & & & & & & & \\
\hline \multicolumn{13}{|l|}{ Education } \\
\hline Primary & & -0.187 & -0.196 & -0.228 & & -0.002 & 0.009 & -0.004 & & 2.1 & -19.3 & 4.2 \\
\hline Secondary & & 0.228 & 0.143 & 0.105 & & 0.009 & -0.005 & 0.000 & & -9.6 & 9.6 & -0.1 \\
\hline Higher & & 0.564 & 0.525 & 0.530 & & 0.002 & -0.021 & -0.023 & & -1.7 & 43.8 & 24.4 \\
\hline \multicolumn{13}{|l|}{ Wealth index } \\
\hline Poorer & & -0.486 & -0.526 & -0.485 & & 0.000 & 0.004 & 0.004 & & 0.2 & -8.9 & -3.9 \\
\hline Middle & & -0.106 & -0.137 & -0.114 & & 0.003 & -0.002 & 0.002 & & -3.5 & 4.6 & -2.2 \\
\hline Richer & & 0.314 & 0.277 & 0.294 & & -0.015 & 0.002 & -0.008 & & 15.1 & -4.4 & 8.7 \\
\hline Richest & & 0.771 & 0.746 & 0.755 & & -0.050 & 0.004 & -0.050 & & 51.1 & -9.1 & 53.1 \\
\hline \multicolumn{13}{|c|}{ Outpatient care utilization } \\
\hline Concentration index & & 0.0821 & 0.0348 & 0.0347 & & & & & & & & \\
\hline \multicolumn{13}{|l|}{ Education } \\
\hline Primary & & -0.187 & -0.196 & -0.228 & & -0.005 & 0.006 & -0.024 & & -6.5 & 17.3 & -68.8 \\
\hline Secondary & & 0.228 & 0.143 & 0.105 & & 0.002 & -0.002 & 0.005 & & 2.7 & -5.6 & 13.3 \\
\hline Higher & & 0.564 & 0.525 & 0.530 & & 0.004 & 0.005 & 0.000 & & 4.5 & 14.8 & 0.4 \\
\hline \multicolumn{13}{|l|}{ Wealth index } \\
\hline Poorer & & -0.486 & -0.526 & -0.485 & & -0.010 & -0.026 & -0.005 & & -12.1 & -74.8 & -15.1 \\
\hline Middle & & -0.106 & -0.137 & -0.114 & & -0.004 & -0.008 & -0.003 & & -5.3 & -23.9 & -9.3 \\
\hline Richer & & 0.314 & 0.277 & 0.294 & & 0.029 & 0.021 & 0.013 & & 34.7 & 61.6 & 36.7 \\
\hline Richest & & 0.771 & 0.746 & 0.755 & & 0.081 & 0.065 & 0.057 & & 99.0 & 187.6 & 164.8 \\
\hline \multicolumn{13}{|c|}{ Inpatient care utilization } \\
\hline Concentration index & & 0.0496 & 0.0625 & -0.0010 & & & & & & & & \\
\hline \multicolumn{13}{|l|}{ Education } \\
\hline Primary & & -0.187 & -0.196 & -0.228 & & -0.016 & -0.006 & -0.011 & & -33.0 & -9.6 & 113.8 \\
\hline Secondary & & 0.228 & 0.143 & 0.105 & & 0.012 & -0.003 & 0.004 & & 23.2 & -4.3 & -36.8 \\
\hline Higher & & 0.564 & 0.525 & 0.530 & & 0.014 & -0.005 & -0.001 & & 27.8 & -8.2 & 5.2 \\
\hline \multicolumn{13}{|l|}{ Wealth index } \\
\hline Poorer & & -0.486 & -0.526 & -0.485 & & -0.013 & -0.014 & -0.016 & & -27.2 & -22.7 & 161.9 \\
\hline Middle & & -0.106 & -0.137 & -0.114 & & -0.003 & -0.013 & -0.005 & & -6.1 & -21.4 & 50.4 \\
\hline
\end{tabular}


Table 3 Decomposition analysis of inequalities in NHIPa coverage, self-reported illness, and healthcare utilization ${ }^{\mathrm{b}}$ among older adults in the Philippines, 2003-2017 (Continued)

\begin{tabular}{|c|c|c|c|c|c|c|c|c|c|c|c|c|}
\hline \multirow[t]{2}{*}{ Variables } & \multicolumn{4}{|c|}{ Concentration index $(C)$} & \multicolumn{4}{|c|}{ Absolute contribution to $C^{c}$} & \multicolumn{4}{|c|}{ Percentage contribution to $C^{c}(\%)$} \\
\hline & 2003 & 2008 & 2013 & 2017 & 2003 & 2008 & 2013 & 2017 & 2003 & 2008 & 2013 & 2017 \\
\hline Richer & & 0.314 & 0.277 & 0.294 & & 0.012 & 0.017 & 0.022 & & 23.4 & 27.6 & -222.2 \\
\hline Richest & & 0.771 & 0.746 & 0.755 & & 0.040 & 0.050 & 0.029 & & 81.0 & 80.2 & -291. \\
\hline
\end{tabular}

Data for self-reported illness, outpatient care utilization, and inpatient care utilization were not included in the 2003 survey

${ }^{a}$ National Health Insurance Program

${ }^{b}$ Outpatient care utilization and inpatient care utilization

${ }^{c}$ Concentration index

"indigent." Major advancements were implemented towards covering the poorest sector of the population and improving access to quality care, such as the enrollment of poor families, the reduction of hospital fees in government facilities, the allocation of revenues for health, and the expansion of NHIP coverage to include all senior citizens beginning in 2014. The commencement of the Kalusugang Pangkalahatan, or the Universal Health Coverage, to address inequities in the health system in 2010 was composed of upgrading facilities under the Health Facilities Enhancement Program (HFEP) to become accredited for Primary Care Benefits beginning in 2012, extending subsidies to the poor and the near poor in 2013 [26], and the mandatory enrollment of senior citizens aged 60 years or older in PhilHealth in 2014. The budget for HFEP reported an increase from PHP 3.25 billion (Philippine peso) in 2010 to PHP 26 billion in 2016 [9]. Republic Act 10645, an act providing mandatory PhilHealth coverage for all senior citizens [27], attempted to provide financial risk protection and access to essential health services by qualifying Filipino citizens who are residents of the Philippines aged 60 years or older and who are not currently covered by any membership category of PhilHealth. By virtue of this Act, a total of 5.8 million older adults were automatically enrolled in PhilHealth in 2015 [9] which later on increased to 6.9 million in 2017 [28].

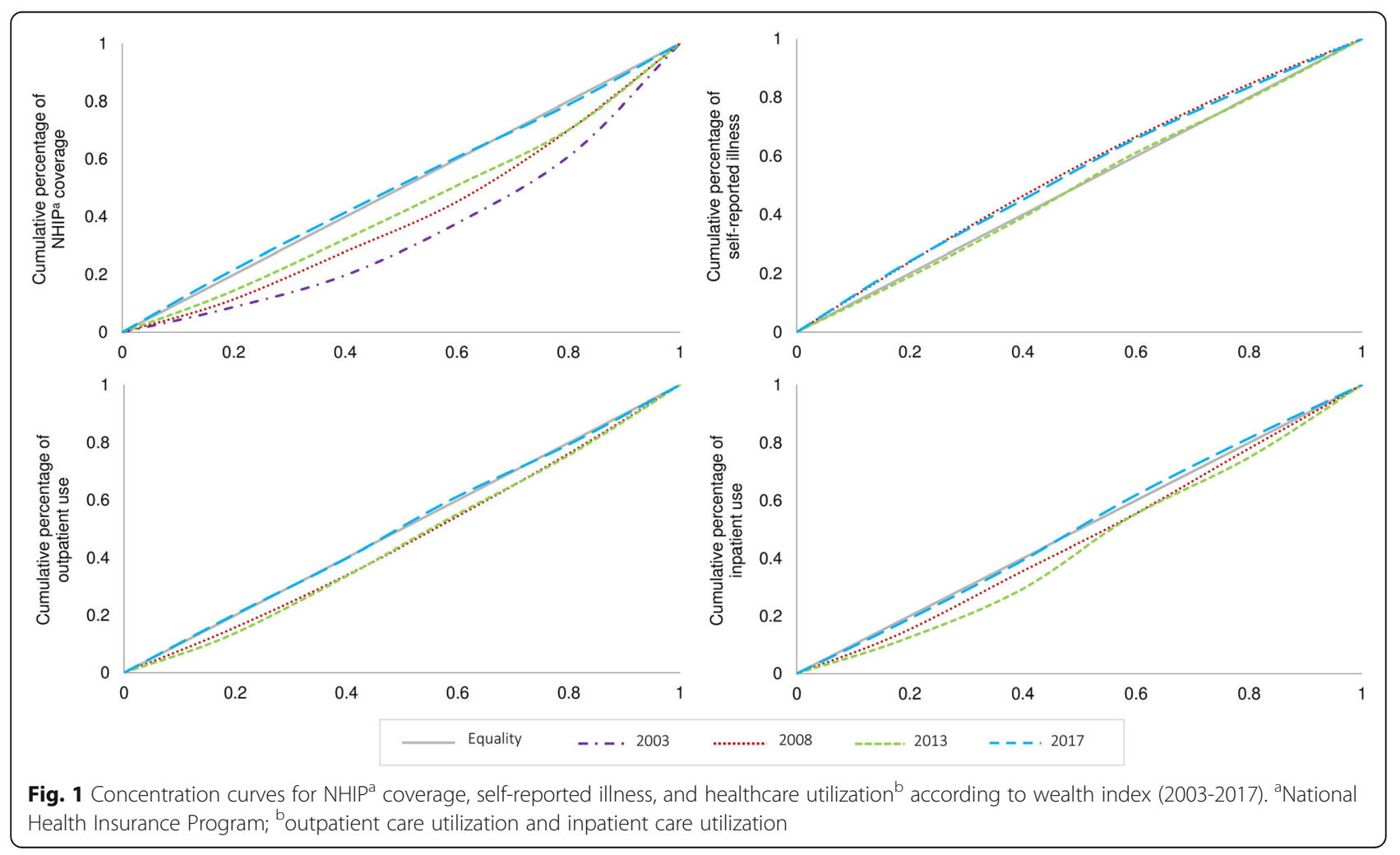


The premium contributions for recipients of the mandatory membership under the senior citizen category are sourced from revenue from the Sin Tax Law (Republic Act 10351), which assists in the financing of the UHC program [29]. From 2015, the proceeds of the Sin Tax Law were allocated toward the NHIP premiums for both poor and older adults. Overall, 67.5\% of older adults included in the senior citizen program of PhilHealth in 2015 reported that they had not had previous coverage. Policies to increase healthcare access through minimizing the social gradient in health were the implementation of the "No Balance Billing" which explicitly forbids government-owned hospitals from charging patients additional fees above what PhilHealth reimburses for case rates, and the " $\mathrm{Z}$ Benefit Package" which increases financial risk protection through cost-effective interventions.

\section{Socio-economic characteristics}

Table 2 reports the outcome variables for the four surveys according to socio-economic characteristics among older adults. The rates of NHIP coverage in the four surveys were $9.4 \%$ (2003), 35.3\% (2008), 57.9\% (2013), and $87.6 \%$ (2017), showing an increase over the 14-year period. Selfreported illness increased to $28.3 \%$ in 2017 from $20.5 \%$ in 2008. Outpatient care utilization and inpatient care utilization increased from 13.3 in 2008 to $18.7 \%$ in 2017 and from 8.8 in 2008 to $12.4 \%$ in 2017 , respectively.

Wealth is significantly associated with self-reported illness in three of the surveys $(2008: P \leq 0.001$; 2013: $P=$ 0.02 ; 2017: $P \leq 0.001$ ), with the poorest reporting a higher occurrence of disease. Self-reported illness shows positive association with NHIP coverage in 2013 and 2017. Wealth is also significantly associated with outpatient care utilization from 2008 to 2017, with richer individuals reporting higher utilization. Inpatient care utilization from 2013 to 2017 is significantly associated with wealth, but a trend was not observed among wealth quintiles.

Inequalities in NHIP coverage, self-reported illness, outpatient care utilization, and inpatient care utilization Table 3 presents the concentration indexes, and Fig. 1 illustrates the concentration curves for NHIP coverage, self-reported illness, outpatient care utilization, and inpatient care utilization. The concentration index for NHIP coverage was 0.3000 in 2003 and 0.0247 in 2017. Figure 1 illustrates a pro-rich inequality in NHIP coverage, which indicates that NHIP coverage is more prevalent among wealthier older adults. Self-reported illness shows a propoor inequality for 2008 to 2017, with a concentration index of -0.0972 and -0.0965 , respectively. This demonstrates that the greater proportion of older Filipino adults reporting the presence of illness is poor. Furthermore, a decrease in the concentration index of self-reported illness was observed between 2008 and 2013, with a value of 0.0972 and -0.0474 , respectively.

Outpatient care utilization shows a pro-rich inequality, with a decrease in the concentration index from 0.0821 (2008) to 0.0347 (2017); this change moved the concentration curve to a position almost equivalent to the line of equity. For inpatient care utilization, a positive concentration index of 0.0496 in 2008 increased to 0.0625 in 2013, both denoting a pro-rich inequality. Following 2013 , the concentration index shifted to a negative value of -0.0010 in 2017 , revealing a pro-poor inequality, indicating that poorer older adults use inpatient care more than the wealthier groups.

\section{Decomposition analysis of socio-economic inequalities}

Table 3 presents the contributions of education and wealth to socio-economic inequalities. The contributions of older adults belonging to a wealthier group were $48.3 \%$ (2003), 66.3\% (2008), $59.5 \%$ (2013), and $75.5 \%$ (2017), explaining the pro-rich inequality in NHIP coverage. For self-reported illness, the contribution of urban residence decreased to 5.3\% (2017) from $25.4 \%$ (2008) and $45.9 \%$ (2013). For outpatient care utilization, the percentage contribution of having a secondary education or higher increases from 7.2 in 2008 to $13.7 \%$ in 2017. The wealth index shows a decrease in its contribution to the concentration index of inpatient care utilization from 2008 to 2017.

\section{Discussion}

Less than half of older adults living in the Philippines were covered by the NHIP between 2003 (9.4\%) and 2008 (35.3\%); an increase was observed in 2013 (57.9\%), and the majority of older adults were covered in 2017 (87.6\%) after the implementation of the NHIP coverage expansion among older adults. These findings showed an increase in NHIP coverage among poorer older adults from 2003 to 2017, despite the persistence of a pro-rich inequality (Fig. 1). Laws and policies have been mandated to increase subsidized NHIP coverage among indigents and older adults, with participation from local government units (LGU) and the DOH.

\section{Equity in NHIP coverage}

Our study showed a decline in socio-economic inequalities in NHIP coverage after the mandatory NHIP coverage for older adults, as indicated by the increase in coverage between 2003 and 2017. Between 2003 and 2008, several laws were enacted, such as the granting of additional benefits and privileges to older adults, subsidies for NHIP premium contributions for indigent members by LGUs and the national government, the enrollment of an additional 4.2 million poor families into the NHIP, and the allocation of $2.5 \%$ of government 
revenues from taxes on "sin" products to the NHIP, which contributed to a substantial increase in new coverage [30].

Further initiatives were enacted between 2010 and 2014, such as the implementation of Universal Health Care or Kalusugang Pangkalahatan to address inequity in the health system, the "No Balance Billing" Policy protecting the poor from paying fees in excess of the NHIP coverage at government facilities, the Sin Tax Law that subsidizes NHIP coverage premiums, the introduction of Z-Benefits [2], which aims to cover the expenses of costly procedures, and the introduction of the Expanded Senior's Citizens' Act of 2010 stipulating the automatic NHIP coverage of all indigent older adults and later on amended to include the mandatory enrollment of all adults aged 60 years or older into the NHIP in 2014 [4]. The DOH reported that by 2015 , a total of 5.8 million older adults had been automatically enrolled in PhilHealth, and a Sin Tax Law incremental revenue of PHP 31.26 billion was allocated in 2016 to cover the 1-year NHIP premium subsidies of indigents and older adults not covered by the NHIP, representing a $248 \%$ increase from the $2013 \mathrm{DOH}$ budget level [31]. So far, no data has been reported evaluating whether the goals of these laws and initiatives have been achieved, but we can speculate that the reduction in inequalities in NHIP coverage is related to the expansion of NHIP coverage for older adults. The government's initiative to expand NHIP coverage was sequentially followed by older adults gaining easier access to NHIP coverage regardless of their wealth status; however, causal inferences are unascertained in the present study.

With advancements in NHIP coverage expansion and increased allocation for NHIP premium subsidies, out of pocket spending remains to gather the majority portion of total health expenditure, covering 53.7\% in 2014 [6]. Utilization of healthcare services largely depends on the household's ability to pay, with the share of PhilHealth in total health expenditure at only $14 \%$ [2].

\section{Health inequalities}

Following the expansion in NHIP coverage among older adults in 2014, decrease in healthcare utilization inequalities was observed. The negative concentration index for self-reported illness in 2008, 2013, and 2017 indicated a concentration among the poorer population. Health policy reforms on increasing health insurance coverage may have contributed to the increase access to healthcare services such as diagnosis and treatment [32] leading to a better health outcome [33]. The financial risk protection afforded by the revenue for health from the Sin Tax Law expanded the DOH's budget and enabled greater medical assistance, with a figure of 24,009 indigents benefiting in 2013 and 363,900 benefiting in 2016 [31].
The concentration of self-reported illness among older adults with lower income may also be explained by a decreased means of affording healthcare, leading to an inability to respond to healthcare needs, in contrast to richer individuals with the ability to purchase healthcare services [34, 35]. Pathways linking income inequality and health have been reported in past years, suggesting that income poverty is a risk factor for premature mortality and increased morbidity [36, 37]. A study done in the USA suggested that poverty is considered to be the primary influence in access to healthcare among the elderly [38].

\section{Access to healthcare}

The concentration index for inpatient care utilization shifted from being pro-rich between 2008 and 2013 to being pro-poor inequality in 2017, 3 years after the initiation of the expansion of NHIP coverage to include older adults. Inequalities were reduced as evidenced by the concentration indexes moving towards a score of 0 and the concentration curves situated close to or over the line of equity. The initiation of laws, such as providing discounts, free healthcare utilization and medicines in government hospitals, and the mandatory enrollment of older adults into the NHIP, was sequentially followed by a narrowing of socio-economic inequalities and an increase in the utilization of healthcare services among older adults.

Risk factors such as wealth and education are important contributors to health utilization inequalities based on decomposition analyses $[12,39]$. Various health conditions, an older age, and the availability of health insurance play important roles in enabling the use of certain services more than others [20]. Studies in LMICs have reported that wealth status or economic factors are associated with healthcare utilization $[19,20]$, similar to the results in high-income countries [38]. Furthermore, the present findings are consistent with those of a study done in China showing a pro-rich inequality in inpatient utilization, indicating that a disproportionate share of inpatient resources are utilized by wealthier individuals with lower health needs [13]. An increase in socio-economic inequality of inpatient utilization was observed in 2013 compared to 2008, considering the policies on increasing financial risk protection put in place (Table 1). PhilHealth benefit utilization remained low despite increase in NHIP coverage. Low PhilHealth utilization rates may be explained by the avoidance of the poor to seek care in hospitals because of catastrophic medical expenses that hospitalization requires, or scarcity of health workforce and facilities capable to provide quality care in geographically isolated areas, leading to unattainable healthcare services [40].

Meanwhile, a pro-poor inequality was observed for inpatient utilization in 2017, which can be explained by individuals belonging to the poorer quintiles reporting a greater proportion of inpatient care use, compared with 
those in the wealthier cohort, following the expansion of NHIP coverage among older adults, despite the strong pro-rich inequality in healthcare use reported in previous studies [12,13]. This change may be attributable to new laws and policies mandating free medical and dental services in 2010 and the mandatory inclusion of individuals aged 60 years or older in the "No Balance Billing" policy of PhilHealth in 2015 [41, 42]. Furthermore, the increased budget allocation for the HFEP, which provides primary care benefits, might have contributed to easier access to quality healthcare for older Filipino adults.

Data from the year 2017 showed a higher utilization of both outpatient and inpatient healthcare services, compared with previous years. Despite having a lesser need for healthcare services, richer individuals generally utilize more health services than poorer individuals, suggesting that income is the principal determinant of the pro-rich inequality in healthcare utilization [13]. Therefore, wealthier older adults pay for more services, regardless of need. Research examining healthcare utilization among older adults with cardiovascular diseases reported that older age, gender, higher household wealth status, higher education, and health insurance were associated with outpatient care utilization $[19,20,39]$, while only age and health insurance were associated with inpatient care utilization [19]. In contrast, a study done in Indonesia revealed that an older adult's insurance status was associated with a higher use of inpatient services and that the use of outpatient services varied among regions [43], which may be explained by the partial resolution of financial barriers to care and differences in healthcare coverage/availability of service providers, respectively. A report that health insurance is a strong contributor to inpatient care utilization among older adults [19] supports our findings of a pro-poor inequality for inpatient care utilization following NHIP coverage expansion. Aside from minimizing socio-economic inequalities in healthcare utilization, achieving good health outcomes is of equal importance. Furthermore, decrease in outpatient care utilization inequality was also observed but remained pro-rich before and after the NHIP coverage expansion policy. Political commitment encompassing experimental verification, risk analysis, and sustained citizen education [44] must be ensured not only to expand healthcare coverage but also to guarantee affordability and the availability of various benefit packages [45].

\section{Strengths and limitations}

The methodological strengths of this study include the calculation of the concentration index and the decomposition analysis of $C$. The concentration index includes all individuals in its calculation and is sensitive to changes in the distribution of health and healthcare utilization within the population across different socio-economic categories [46], while decomposition analysis of the concentration index was applied to determine the contributions of socioeconomic variables and individual characteristics on health and healthcare utilization inequalities in nationally representative samples. Next, the study analyzed the change in socio-economic inequalities in NHIP coverage, health, and healthcare utilization among older adults in the Philippines before and after the NHIP coverage expansion in the older adult population. However, the present study has some potential limitations, and caution is needed in interpreting trends in health and healthcare utilization based on the DHS wealth index, considering that the index shows a relative position measured using a composite economic status indicator among the participants of a particular year and country, which prevents the wealth index scores for different years from being compared [47]. Furthermore, the cross-sectional data used cannot be employed to infer causality. The DHS performed in the Philippines was not designed to fill a gap in research on ageing specifically, which limited the variables that could be used to explain inequalities in health among older adults accurately. The reporting of illness is subjective and cannot be used to determine severity precisely. $\mathrm{NCD}, \mathrm{CD}$, and injuries also present differences in medical-seeking behavior, depending on the disease severity. Likewise, healthcare utilization is also subjective; therefore, the utilization of inpatient services, for example, does not necessarily mean that those utilizing the services are ill or that their health conditions require hospitalization. DHS data does not distinguish between the use of private health facilities accredited by PhilHealth and those not accredited at the time of interview; therefore, the data used is unable to ascertain that increase access to healthcare is solely contributed by NHIP. Furthermore, the self-reporting of healthcare use cannot be used to determine whether those who utilized outpatient services also utilized inpatient services as recommended by a healthcare professional. Identifying mortality through using death information in health insurance claims databases [48] may be considered to assess inequalities in healthcare use in future researches. Lastly, it is worth noting that despite the resulting massive coverage of older adults in the NHIP, this populist policy offering free healthcare may cause an overuse of services leading to a heavy financial burden on the Philippine health system, as experienced in Japan, wherein challenges such as financial sustainability and equity remain, and actions to reduce healthcare expenditures have led to the abolishment of free healthcare for older adults, the requirement of a $10 \%$ out-of-pocket fee, and an increase in the age of eligibility [5].

\section{Conclusions}

Overall, the results presented an increase in the percentage of and a reduction in socio-economic inequalities in 
NHIP coverage, health, and healthcare utilization among older adults, especially those belonging to lower-income groups. The sequential outcomes following instituted health and social policies showed that increased investment in NHIP coverage expansion led not only to a decline in health and healthcare utilization inequalities but also enabled equal opportunities to access health services, which is a major component leading towards UHC.

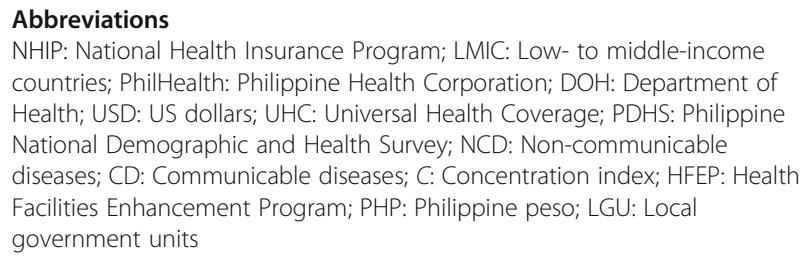
countries; PhilHealth: Philippine Health Corporation; DOH: Department of Health; USD: US dollars; UHC: Universal Health Coverage; PDHS: Philippine National Demographic and Health Survey; NCD: Non-communicable diseases; CD: Communicable diseases; C: Concentration index; HFEP: Health Facilities Enhancement Program; PHP: Philippine peso; LGU: Local government units

\section{Acknowledgements}

The authors are grateful to ICF International, Rockville, Maryland, USA through Measure DHS Program for granting us permission to access the 2003, 2008, 2013, and 2017 Philippine National Demographic and Health Surveys, and to all individuals and institutions involved in conducting the survey.

\section{Authors' contributions}

KLS and KN conceptualized and designed the study. KLS performed statistical analysis. KLS, KN, and $\mathrm{KS}$ analyzed and interpreted statistical data. KLS prepared the manuscript. KN and KS reviewed and provided conceptual advice for the manuscript. All authors read and approved the final manuscript.

\section{Funding}

This research was supported by the World Health Organization Centre for Health Development (WHO Kobe Centre - WKC: K18017).

\section{Availability of data and materials}

The datasets analyzed during the current study are available in the DHS data repository: https://www.dhsprogram.com/.

\section{Ethics approval and consent to participate}

The survey protocols were reviewed and approved by the ICF Institutional Review Board.

\section{Consent for publication}

Not applicable.

\section{Competing interests}

The authors declare that they have no competing interests.

Received: 6 January 2020 Accepted: 17 May 2020

Published online: 09 June 2020

\section{References}

1. Department of Economic and Social Affairs PD, United Nations. World Population Ageing 2017 report. 2017;1-124. http://www.un.org/en/ development/desa/population/publications/pdf/ageing/WPA2017_Report. pdf. Accessed 07 Jan 2020.

2. Obermann $\mathrm{K}$, Jowett $\mathrm{M}$, Kwon $\mathrm{S}$. The role of national health insurance for achieving UHC in the Philippines: a mixed methods analysis. Glob Health Action. 2018;11(1).

3. Madore A, Rosenberg J, Weintraub R. "Sin Taxes" and health financing in the Philippines. Massachusetts, Boston: Harvard Business Publishing; 2015. http://www.globalhealthdelivery.org/files/ghd/files/ghd-030_philippines_ tobacco_control_teaching_case.pdf.

4. Congress of the Philippines. Republic Act No. 10645 an act providing for the mandatory Philhealth coverage for all senior citizens. 2014. https://www. doh.gov.ph/sites/default/files/policies_and_laws/ra.10645.pdf.
5. Sakamoto H, Rahman M, Nomura S, Okamoto E, Koike S, Yasunaga H, et al. Japan health system review. Regional Office for South-East Asia: New Delhi; 2018. http://apps.who.int/iris/bitstream/handle/10665/259941/ 9789290226260-eng.pdf;jsessionid=793E7F28273806A2F763882D242BCB1 A? sequence $=1$.

6. Dayrit MM, Lagrada LP, Picazo OF, Pons MC, Villaverde MC. The Philippines health system review. Regional Office for South-East Asia: New Delhi; 2018. https:/apps.who.int/iris/bitstream/handle/10665/274579/9789290226734eng.pdf? sequence $=1$ \&isAllowed $=y$.

7. Son HH. Equity in health and health care in the Philippines. Asian Development Bank: Mandaluyong, Philippines; 2009. https://www.adb.org/ sites/default/files/publication/28390/economics-wp171.pdf.

8. Khan JAM, Ahmed S, MacLennan M, Sarker AR, Sultana M, Rahman H. Benefit incidence analysis of healthcare in Bangladesh - equity matters for universal health coverage. Health Policy Plan. 2017;32(3):359-65.

9. Health Policy Development and Planning Bureau, Department of Health, Philippines. Kalusugan pangkalahatan 2010-2016: an assessment report. 2016;1-23. https://www.doh.gov.ph/sites/default/files/publications/ Kalusugan_Pangkalahatan2010-2016_An\%20Assessment_Report. compressed.pdf. Accessed 29 Dec 2018.

10. Brinda EM, Attermann J, Gerdtham UG, Enemark U. Socio-economic inequalities in health and health service use among older adults in India: results from the WHO Study on Global AGEing and adult health survey. Public Health. 2016;141:32-41.

11. Yiengprugsawan V, Lim LLY, Carmichael GA, Sidorenko A, Sleigh AC. Measuring and decomposing inequity in self-reported morbidity and selfassessed health in Thailand. Int J Equity Health. 2007;6(23):1-17.

12. Fu X, Sun N, Xu F, Li J, Tang $Q$, He J, et al. Influencing factors of inequity in health services utilization among the elderly in China. Int J Equity Health. 2018;17(1):144.

13. Zhou Z, Gao J, Fox A, Rao K, Xu K, Xu L, et al. Measuring the equity of inpatient utilization in Chinese rural areas. BMC Health Serv Res. 2011; 11(201):1-12.

14. National Statistics Office Philippines, ORC Macro. National demographic and health survey 2003. Calverton, Maryland: National Statistics Office and ORC Macro; 2004 Oct. http://dhsprogram.com/pubs/pdf/FR156/FR156.pdf. Accessed 07 Jan 2020.

15. National Statistics Office Philippines, ICF Macro. National demographic and health survey 2008. Calverton, Maryland: National Statistics Office and ICF Macro; 2009 Dec. https://dhsprogram.com/pubs/pdf/FR224/FR224.pdf. Accessed 07 Jan 2020

16. Philippine Statistics Authority (PSA) Philippines, ICF International. National demographic and health survey 2013. Manila, Philippines, Rockville, Maryland: PSA and ICF International; 2014 Aug. Accessed 07 Jan 2020 https://dhsprogram.com/pubs/pdf/FR294/FR294.pdf.

17. Philippine Statistics Authority (PSA), ICF International. National demographic and health survey 2017. Quezon city, Philippines and Rockville, Maryland: PSA and ICF; 2018 Oct. https://dhsprogram.com/pubs/pdf/FR347/FR347.pdf. Accessed 07 Jan 2020.

18. Gouda HN, Hodge A, Bermejo R III, Zeck W, Jimenez-Soto E. The impact of healthcare insurance on the utilisation of facility-based delivery for childbirth in the Philippines. PLoS One. 2016;11(12):1-15.

19. Dou L, Liu X, Zhang T, Wu Y. Health care utilization in older people with cardiovascular disease in China. Int J Equity Health. 2015;14(1):1-8.

20. Wong R, Díaz JJ. Health care utilization among older Mexicans: health and socioeconomic inequalities. Salud Publica Mex. 2007:49(Suppl 4):S505-14.

21. Landerman LR, Fillenbaum GG, Pieper CF, Maddox GL, Gold DT, Guralnik JM. Private health insurance coverage and disability among older Americans. J Gerontol B Psychol Sci Soc Sci. 1998;53(5):S258-66.

22. Peltzer K, Williams JS, Kowal P, Negin J, Snodgrass JJ, Yawson A, et al. Universal health coverage in emerging economies: findings on health care utilization by older adults in China, Ghana, India, Mexico, the Russian Federation, and South Africa. Glob Health Action. 2014;7(25314):1-5.

23. O'Donnell O, van Doorslaer E, Wagstaff A, Lindelow M. Analyzing health equity using household survey data: a guide to techniques and their implementation. Washington, DC: The World Bank; 2007. https:/elibrary. worldbank.org/doi/abs/10.1596/978-0-8213-6933-3. doi: https://doi.org/10. 1596/978-0-8213-6933-3. Accessed 29 Nov 2018.

24. Zere E, Oluwole D, Kirigia JM, Mwikisa CN, Mbeeli T. Inequities in skilled attendance at birth in Namibia: a decomposition analysis. BMC Pregnancy Childbirth. 2011 May;11(34):1-10. 
25. Philippine Health Insurance Corporation. The PhilHealth chronicles: the journey towards universal social health insurance. Pasig city, Philippines: Corporate Planning Department, Philippine Health Insurance; 2004.

26. Congress of the Philippines. Republic Act No. 10606 an act amending Republic Act No. 7875. 2013. https://www.philhealth.gov.ph/about_us/ ra10606.pdf

27. HelpAge International. Global Age Watch Index 2015. 2015. https://www. helpage.org/global-agewatch/population-ageing-data/country-ageing-data/ ?country=Philippines.

28. Philippine Health Insurance Corporation. 2017 Annual report. 2017. https:// www.philhealth.gov.ph/about_us/annual_report/ar2017.pdf.

29. Congress of the Philippines. Republic Act No. 10351 an act restructuring the excise tax on alcohol and tobacco products. 2012. https://www.doh.gov.ph/ sites/default/files/policies_and_laws/RA10351.pdf.

30. Bredenkamp C, Capuno J, Kraft A, Poco L, Quimbo S, Tan CA. Expansion of health insurance in the Philippines: evidence from panel data. Washington, DC: The World Bank; 2017 Mar. https://openknowledge.worldbank.org/ handle/10986/27669.

31. Department of Health, Philippines. Sin tax law incremental revenue for health annual report C.Y. 2016. 2016. https://www.doh.gov.ph/sites/default/ files/publications/2016\%20DOH\%20Sin\%20Tax\%20Report.pdf DOH Sin Tax Report.pdf. Accessed 03 Sep 2019.

32. Erlangga D, Suhrcke M, Ali S, Bloor K. The impact of public health insurance on health care utilisation, financial protection and health status in low- and middle- income countries: a systematic review. PLoS One. 2019;14(11):1-20.

33. Quimbo SA, Peabody JW, Shimkhada R, Florentino J, Solon O. Evidence of a causal link between health outcomes, insurance coverage and a policy to expand access: experimental data from children in the Philippines. Health Econ. 2011;20(5):620-30.

34. Fonta CL, Nonvignon J, Aikins M, Nwosu E, Aryeetey GC. Predictors of selfreported health among the elderly in Ghana: a cross sectional study. BMC Geriatr. 2017;17(1):1-15.

35. Sun Q, Liu X, Meng Q, Tang S, Yu B, Tolhurst R. Evaluating the financial protection of patients with chronic disease by health insurance in rural China. Int J Equity Health. 2009;8:1-10.

36. Kondo N. Socioeconomic disparities and health: impacts and pathways. J Epidemiol. 2012;22(1):2-6.

37. Kondo N, Kawachi I, Hirai H, Kondo K, Subramanian SV, Hanibuchi T, et al. Relative deprivation and incident functional disability among older Japanese women and men: prospective cohort study. J Epidemiol Community Health. 2009;63(6):461-7.

38. Fitzpatrick AL, Powe NR, Cooper LS, Ives DG, Robbins JA, Enright E. Barriers to health care access among the elderly and who perceives them. Am J Public Health. 2004;94(10):1788-94.

39. Awoke MA, Negin J, Moller J, Farell P, Yawson AE, Biritwum RB, et al. Predictors of public and private healthcare utilization and associated health system responsiveness among older adults in Ghana. Glob Health Action [Internet]. 2017;10(1).

40. Banaag MS, Dayrit MM, Mendoza RU. Health inequity in the Philippines. In: Batabyal AA, Higano Y, Nijkamp P, editors. Disease, human health, and regional growth and development in Asia. Singapore: Springer; 2019. p. 163-74.

41. Congress of the Philippines. Republic Act No. 9994 an act granting additional benefits and privileges to senior citizens. 2010. https://www. officialgazette.gov.ph/2010/02/15/republic-act-no-9994/. Accessed 08 Mar 2019.

42. Philippine Health Insurance Corporation. PhilHealth circular 2017-0017 Strengthening the implementation of the No Balance Billing policy (revision 2). 2017. https://www.philhealth.gov.ph/circulars/2017/circ2017-0017.pdf.

43. Madyaningrum E, Chuang YC, Chuang KY. Factors associated with the use of outpatient services among the elderly in Indonesia. BMC Health Serv Res. 2018;18(1):707.

44. Reis J, Spencer PS. Decision-making under uncertainty in environmental health policy: new approaches. Environ Health Prev Med. 2019;24(1):1-8.

45. Van Minh H, Lucero-Prisno DE III, Ng N, Phaholyothin N, Phonvisay A, Soe KM, et al. Progress toward universal health coverage in ASEAN. Glob Health Action. 2015;8:1-12.

46. Regidor E. Measures of health inequalities: part 2. J Epidemiol Community Health. 2004;58(11):900-3.
47. Molina HF, Nakamura K, Kizuki M, Seino K. Reduction in inequality in antenatalcare use and persistence of inequality in skilled birth attendance in the Philippines from 1993 to 2008. BMJ Open. 2013;3(6):1-8.

48. Sakai M, Ohtera S, Iwao T, Neff Y, Kato G, Takahashi Y, et al. BiDAME (Big Data Analysis of Medical care for the Elderly in Kyoto). Validation of claims data to identify death among aged persons utilizing enrollment data from health insurance unions. Environ Health Prev Med. 2019;24(1):1-6.

\section{Publisher's Note}

Springer Nature remains neutral with regard to jurisdictional claims in published maps and institutional affiliations.
Ready to submit your research? Choose BMC and benefit from:

- fast, convenient online submission

- thorough peer review by experienced researchers in your field

- rapid publication on acceptance

- support for research data, including large and complex data types

- gold Open Access which fosters wider collaboration and increased citations

- maximum visibility for your research: over $100 \mathrm{M}$ website views per year

At BMC, research is always in progress.

Learn more biomedcentral.com/submissions 